\title{
Chemokine Signaling Specificity: Essential Role for the N- Terminal Domain of Chemokine Receptors ${ }^{\dagger}$
}

\author{
Gregory N. Prado $\ddagger$, Katsutoshi Suetomi ${ }^{\ddagger}$, David Shumate ${ }^{\ddagger}$, Carrie Maxwell ${ }^{\ddagger}$, Aishwarya \\ Ravindran $\S$, Krishna Rajarathnam $\S$, and Javier Navarro $§,{ }^{*}$ \\ *Department of Neuroscience and Cell Biology, Sealy Centers for Molecular Medicine and Structural \\ Biology and Molecular Biophysics, University of Texas Medical Branch, Galveston, Texas 77555 \\ $\S$ Department of Biochemistry and Molecular Biology, Sealy Centers for Molecular Medicine and \\ Structural Biology and Molecular Biophysics, University of Texas Medical Branch, Galveston, Texas \\ 77555
}

\section{Abstract}

Chemokine IL-8 (CXCL8) binds to its cognate receptors CXCR1 and CXCR2 to induce inflammatory responses, wound healing, tumorogenesis, and neuronal survival. Here we identify the $\mathrm{N}$-loop residues in IL-8 (H18 and F21) and the receptor N-termini as the major structural determinants regulating the rate of receptor internalization, which in turn controlled the activation profile of ERK1/2, a central component of the receptor/ERK signaling pathway that dictates signal specificity. Our data further support the idea that the chemokine receptor core acts as a plastic scaffold. Thus, the diversity and intensity of inflammatory and noninflammatory responses mediated by chemokine receptors appear to be primarily determined by the initial interaction between the receptor $\mathrm{N}$-terminus and the N-loop of chemokines.

\begin{abstract}
Chemokines play key roles in inflammation, wound healing, hematopoiesis, embryogenesis, and metastasis. Chemokines trigger transmembrane signaling via activation of a subclass of $\mathrm{G}$ protein-coupled receptors (1). Although chemokine receptors are structurally related and activate the same Gi protein subtype, they trigger diverse cellular responses and show selectivity in their role as coreceptors in the entry of HIV-1 (2,3). Multiple chemokines often bind the same receptor; however, they elicit distinct cellular responses (4-9). The chemokine interleukin-8 (IL- ${ }^{1}$ or CXCL8) and its cognate receptors CXCR1 and CXCR2 are the paradigm of the chemokine receptor system. IL-8 triggers the activation and migration of neutrophils from the circulating blood to sites of injury or infection and also promotes wound healing and neuronal survival $(1,10-12)$. While CXCR1 binds with high affinity only to IL-8, CXCR2 is promiscuous and binds multiple IL-8-related chemokines with high affinity, including GCP-2, NAP-2, MGSA, and ENA-78 $(13,14)$. On the basis of numerous mutagenesis studies, the hypothetical mechanism of IL-8 binding involves the interaction of the N-loop of IL- 8 with the $\mathrm{N}$-terminal domain of the receptor, as well as the binding of the $\mathrm{N}$-terminus (ELR triad) of IL-8 to the extracellular loops of the receptor (14-21). Although CXCR1 and CXCR2 share $77 \%$ amino acid identity, they mediate different cellular responses; thus, binding of IL-8

\footnotetext{
${ }^{\dagger}$ This work was supported by grants from the Welch Foundation and NIH Grants GM64855, EY014218, and AI069152. (C) 2007 American Chemical Society

*To whom correspondence should be addressed: Department of Neuroscience and Cell Biology, University of Texas Medical Branch, 301 University Blvd., Galveston, TX 77555. E-mail: jnavarro@utmb.edu. Phone: (409) 772-5480. Fax: (409) 772-3222.

${ }_{1}^{1}$ Abbreviations: IL-8, interleukin-8; GCP-2, human granulocyte chemotactic protein 2; NAP-2, neutrophil-activating peptide-2; MGSA, melanoma growth-stimulating activity; ENA-78, epithelial neutrophil-activating peptide-78; PTX, pertussis toxin; IP-10, interferon $\gamma$ inducible protein-10; WT, wild type.
} 
to CXCR1 triggers super-oxide production in neutrophils (22), and binding to CXCR2 induces the release of tertiary granules from neutrophils and promotes wound healing and neuronal survival $(10,23,24)$. The mechanisms underlying the signal specificity leading to the distinct cellular responses mediated by CXCR 1 and CXCR 2 are unknown. A major difference between these homologous receptors is that the rate and extent of agonist-induced internalization of CXCR2 are many-fold greater than those of CXCR1 $(25,26)$. In fact, the rate of IL-8-induced internalization of CXCR2 is one of the fastest of all the GPCRs that have been examined; more than $90 \%$ of the receptors are sequestered in less than 2 min after exposure to IL-8. An emerging concept is that the mechanism of signal specificity mediated by GPCRs is determined by receptor trafficking, which could promote receptor signaling from the intracellular compartments, in addition to the initial signaling from the plasma membrane (27). The molecular basis determining the differential receptor trafficking and how it is coupled to signal specificity are currently unknown. Here we report the identification of the molecular interactions between the chemokine IL- 8 and its cognate receptors underlying the chemokineinduced receptor internalization and signal specificity. We found that specific interactions between the N-terminal domains of the chemokine receptors and the N-loop of IL-8 are essential for determining the receptor trafficking profiles, which in turn regulate the signal specificity. Our findings support the hypothesis that the receptor cores (loops, C-terminus, and transmembrane domains) are plastic in their signaling capacities, which are governed by the key interactions between the $\mathrm{N}$-terminus of the receptor and the chemokine.

\section{EXPERIMENTAL PROCEDURES}

\section{Materials}

COS-7 cells and HEK 293 cells were purchased from American Type Culture Collection (Manassas, VA). Fugene 6 (Roche Diagnostic Corp., Indianapolis, IN) was used for all DNA transfections. All tissue culture reagents were from Invitrogen (Carlsbad, CA). ${ }^{125}$ Iodine was obtained from Amersham Biosciences (Piscataway, NJ). Restriction endonucleases were purchased from New England Biolabs, Inc. (Beverly, MA). Oligonucleotides were purchased from Sigma Genosys. Recombinant IL-8 was produced in Escherichia coli and purified as described previously $(28,29)$. All other chemicals were reagent grade and were obtained from Fisher Scientific or Sigma.

\section{Construction of Receptor Chimeras}

Plasmids encoding wild-type (WT) CXCR1 and CXCR2 and N-terminal receptor chimeras were constructed as described previously (14). Briefly, the cDNAs encoding WT rabbit CXCR1 and WT human CXCR2 were cloned in the pSVL expression plasmid (Pharmacia LKB Biotechnology, Inc.). We used rabbit CXCR1 instead of human CXCR1 because some chimeras between the human isoforms are deficient in their ability to bind IL-8 with high affinity and are inactive $(14,34,48)$. In contrast, chimeras between rabbit CXCR1 and human CXCR2 produce functional receptors as evaluated by high-affinity binding to $\left[{ }^{125} \mathrm{I}\right] \mathrm{IL}-8$ and calcium release. Further, rabbit CXCR1 and human CXCR1 share a high degree of sequence homology and most importantly are functionally equivalent (14). To construct the $\mathrm{N}$-terminal receptor chimeras, the cDNA segments encoding the extracellular amino termini of CXCR1 and CXCR2 were reciprocally exchanged. For the N1R2 chimera (CXCR1 N-terminusCXCR2 backbone), a 271 bp XhoI-CelII fragment of CXCR1 containing the first 58 codons was excised from pSVL.CXCR1 and subcloned into a XhoI-CelII-digested pSVL.CXCR2 backbone. For the N2R1 chimera (CXCR2 N-terminus-CXCR1 backbone), a 283 bp XhoI - CelII fragment of CXCR2 containing the first 62 codons was excised from pSVL-.CXCR2 and subcloned into a XhoI-CelII-digested pSVL-.CXCR1 fragment. Subsequently, we created constructs encoding the receptors fused at its $\mathrm{C}$-termini with the rhodopsin $\mathrm{C} 9$ peptide (TETSQVAPA), which is the epitope for the 1D4 Mab. Finally, these constructs were 
subcloned into the pcDNA-4/TO expression plasmid (Invitrogen, Carlsbad, CA). All constructs were verified by nucleotide sequencing (UTMB Protein Chemistry Core Facility).

\section{Cell Culture and Transfection}

COS-7 cells were cultured in Dulbecco's modified Eagle's medium (DMEM)/F12 medium supplemented with $8 \%$ fetal bovine serum (FBS) and $1 \%$ penicillin/streptomycin (PS). Human embryonic kidney (HEK-293) cells were cultured in high-glucose DMEM supplemented with $5 \%$ FBS and $1 \%$ PS. Cells were incubated at $37^{\circ} \mathrm{C}$ in a $5 \% \mathrm{CO}_{2}$ incubator. Cells in $100 \mathrm{~mm}$ culture dishes were transiently transfected with $4.8 \mu \mathrm{g}$ of plasmid encoding CXCR1, CXCR2, and its N-terminal chimeras using Fugene 6 (Roche Applied Sciences, Indianapolis, IN) as the transfection reagent. The transfected cells were split the next day into 24-well dishes for receptor binding and internalization. All assays were performed $48 \mathrm{~h}$ after transfection.

\section{Radioligand Binding Assays}

[ $\left.{ }^{125} \mathrm{I}\right] \mathrm{IL}-8$ binding was carried out as described previously (30). Briefly, 2 days after transfection, COS-7 cells were incubated with $2 \mathrm{nM}\left[{ }^{125} \mathrm{I}\right]-\mathrm{IL}-8$ in binding buffer [ $1 \times \mathrm{PBS}, 20$ $\mathrm{mM}$ HEPES ( $\mathrm{pH} 7.4$ ), and $0.1 \%$ bovine serum albumin] in the absence or presence of various concentrations of unlabeled chemokines for $2 \mathrm{~h}$ at $4{ }^{\circ} \mathrm{C}$. The binding reaction was terminated by washing the cells three times with ice-cold binding buffer. The cells were solubilized with $0.2 \%$ SDS, and the amount of $\left[{ }^{125} \mathrm{I}\right]-\mathrm{IL}-8$ bound to the cells was determined in a $\gamma$ counter. Nonlinear curve fittings were performed using Sigmaplot, version 9 (SPSS Science, Chicago, IL).

\section{Receptor Internalization}

Transiently transfected COS-7 cells seeded in 24-well dishes were incubated with $100 \mathrm{nM}$ ELR chemokines at $37^{\circ} \mathrm{C}$ for various amounts of time. The cells were then washed with ice-cold PBS containing $20 \mathrm{mM}$ HEPES (pH 7.4) and 0.1\% BSA. To remove cell surface-bound ELR chemokines, the cells were treated with $0.5 \mathrm{~mL}$ of an ice-cold acid solution $[0.2 \mathrm{M}$ acetic acid (pH 3.0) and $0.5 \mathrm{M} \mathrm{NaCl}$ ] for 5 min at $4{ }^{\circ} \mathrm{C}$. To assess the surface binding after the cells were pretreated with $100 \mathrm{nM}$ ELR chemokines, the cells were incubated with $2 \mathrm{nM}{ }^{125}$ I-labeled IL-8 in the absence (total binding) or presence of $200 \mathrm{nM}$ unlabeled IL-8 (nonspecific binding). Cells were washed three times with ice-cold PBS and solubilized with $0.2 \%$ SDS. Cellassociated radioactivity was determined in a $\gamma$ counter.

\section{ERK1/2 Phosphorylation}

Transiently transfected COS-7 cells were seeded into a six-well plate at a density of $3 \times 10^{5}$ cells/well. The cells were serum-starved for $16 \mathrm{~h}$ and then treated with $100 \mathrm{nM} \mathrm{IL-} 8$ for various amounts of time. Cell cultures were quickly rinsed twice with ice-cold PBS and then incubated with $0.4 \mathrm{~mL}$ of ice-cold lysis buffer containing a cocktail of protease inhibitors (Roche Diagnostics). The cell lysates were centrifuged at $4{ }^{\circ} \mathrm{C}$ for $10 \mathrm{~min}$ at $14000 \mathrm{~g}$, and the supernatants were kept at $20^{\circ} \mathrm{C}$ in SDS-PAGE sample buffer containing 2-mercaptoethanol. Proteins in the lysates were fractionated on a 4 to $20 \%$ SDS_PAGE mini-electrophoresis gel and then electroblotted onto a $0.45 \mu \mathrm{m}$ pore size nitrocellulose membrane. The blots were probed with anti-phospho-ERK antibodies (Cell Signaling Technology Inc., Beverly, MA) and detected using an ECL chemiluminescence kit (Pierce Biotechnology, Rockford, IL). Blots were stripped using a stripping buffer (Pierce Biotechnology) and reprobed with an anti-ERK antibody.

\section{Calcium Measurements}

IL-8-induced mobilization of intracellular $\mathrm{Ca}^{2+}$ was carried out as described previously (25, 29). Transiently transfected HEK293 cells were first washed with PBS and then incubated for 
$1 \mathrm{~h}$ at $37{ }^{\circ} \mathrm{C}$ in the dark with $2 \mu \mathrm{M}$ cell-permeant Indo1-AM (Molecular Probes, Eugene, OR) in physiological buffer [140 mM NaCl, $5 \mathrm{mM} \mathrm{KCl}, 0.5 \mathrm{mM} \mathrm{MgCl}_{2}, 1.5 \mathrm{mM} \mathrm{CaCl}_{2}, 10 \mathrm{mM}$ glucose, $10 \mathrm{mM}$ HEPES (pH 7.4), and $0.1 \%$ bovine serum albumin]. Cells were washed in physiological buffer, and the IL-8-induced mobilization of intracellular calcium was monitored by the changes in the Indo-1 fluorescence, using an excitation wavelength of $330 \mathrm{~nm}$ and an emission wavelength of $405 \mathrm{~nm}$ in a Shimadzu RF-5301PC fluorimeter.

\section{RESULTS}

\section{ELR Chemokines Trigger Distinct Rates of Internalization of CXCR2}

Because CXCR2 binds multiple ELR chemokines, we initially examined the effect of saturable concentrations (100 nM) of IL-8, MGSA, and GCP-2 on the rate of internalization of CXCR2. We found that the order of efficiency in triggering internalization of CXCR2 was as follows: IL-8 > MGSA > GCP-2 (Figure 1). These studies are in good agreement with previous semiquantitative analyses of receptor internalization that used fluorescence microscopy to show cytoplasmic localization of the receptor upon chemokine binding $(4,5)$. Although these chemokines bind CXCR2 with similar affinity, they elicit specific cellular responses, suggesting that their mechanisms of binding to the receptor should be different $(6,8)$. Since the $\mathrm{N}$-loop sequence of chemokines is the major determinant for chemokine binding specificity, the rates of receptor internalization could also be determined by the interaction of chemokine $\mathrm{N}$-loop residues with the receptor.

\section{The N-Loop Residues in IL-8 Determine the Rate of Internalization of Chemokine Receptors}

To identify the N-loop IL-8 residues responsible for triggering internalization of the receptor, we examined the role of $\mathrm{H} 18$ and F21, which in our previous studies have been shown to play a role in receptor function and to be part of the epitope of IL-8 neutralizing antibodies (21, 31 ). We previously found that the IL-8 mutants H18A and F21 A not only bind with high affinity to CXCR1 and CXCR2 but also most importantly are agonists in assays of calcium release and secretion of glucoronidase in neutrophils. However, in contrast to wild-type (WT) IL-8, these mutants are poor activators of superoxide production in neutrophils (29). Here we found that binding of the H18A IL-8 mutant failed to trigger internalization of CXCR1 or CXCR2, but F21A elicited internalization of CXCR2, although at rates slower than that of WT IL-8 (Figure 2). Together, these observations suggest that $\mathrm{H} 18$ and $\mathrm{F} 21$ play a key role in governing receptor internalization rates upon binding to CXCR1 and CXCR2. To test whether the ELR triad also influences the rate of internalization of the receptors, we tested the chemokine mutant R6A, which is "inactive" in receptor functional assays and binds these receptors with substantially reduced affinity $(16,17,33)$. Most interestingly, we observed that binding the R6A IL-8 mutant induced internalization of CXCR2 at rates similar to that with WT IL-8 (Figure 3), thus indicating that integrity of the ELR motif is not required for the agonist-induced internalization of the receptor.

\section{The N-Termini of the Receptors Regulate the Rate of Receptor Internalization}

An emerging view in GPCR signaling is that these receptors mediate both a $\mathrm{G}$ proteindependent signaling pathway at the surface of the membrane and $\mathrm{G}$ protein-independent signaling that arises primarily from the cell interior (27). It follows that receptor internalization would play at least a dual role in signaling, terminating $G$ protein-mediated signaling and establishing a $\mathrm{G}$ protein-independent signaling pathway. We and others previously showed that IL-8 binding triggers internalization of CXCR2 at rates many-fold faster than that of CXCR1 in both transfected cell lines and cell types naturally expressing these receptors (25, 34). The rate of receptor internalization is thought to be determined by the $\mathrm{C}$-terminal domains or intracellular loops. This view is supported by data indicating that C-terminal truncation of CXCR1 and CXCR2 disabled internalization of both receptors upon binding to IL-8 $(25,26)$. 
However, receptor chimeras in which the C-termini were reciprocally exchanged between CXCR1 and CXCR2 did not exhibit the corresponding internalization rates (25), suggesting that the $\mathrm{C}$-termini play a passive role in the internalization process. Because the rate of receptor internalization could be determined by the interaction between the IL- $8 \mathrm{~N}$-loop and the receptor $\mathrm{N}$-terminus (Figure 2), we examined whether the extracellular N-terminus contains the molecular information that determines the rate of receptor internalization. We created receptor chimeras in which the N-termini of CXCR1 and CXCR2 were reciprocally exchanged. The N2R1 chimera contained the N-terminus of CXCR2 fused onto the CXCR1 core, and the N1R2 chimera contained the N-terminus of CXCR1 fused onto the CXCR2 core. We observed that both chimeras bound IL- 8 with the same high affinity that the WT receptors did (Figure 1S of the Supporting Information). Furthermore, these chimeras were fully active, as demonstrated by IL-8-induced intracellular calcium release (Figure $2 \mathrm{~S}$ of the Supporting Information). We found that the N2R1 chimera was internalized at a fast rate similar to that for CXCR2, whereas N1R2 was internalized at a slow rate like that for CXCR1 (Figure 4). These findings suggest that the receptor $\mathrm{N}$-termini, regardless of the receptor core, contain the determinants for setting the rate of receptor internalization.

\section{The Rate of Temporal Activation of ERK1/2 Is Determined by the Rate of Receptor Internalization}

ERK/MAP kinases are activated by growth factor receptors and GPCRs, via activation of multiple signaling pathways $(27,35,36)$. The activation of ERK plays pivotal roles in diverse cellular processes, including the determination of cell fate, differentiation, survival, migration, and growth. Importantly, specific cellular responses triggered by the receptors are determined by the cell type-specific regulation of receptor/ERK signaling (37). For example, NGF treatment of PC12 cells induces differentiation and requires Rap stimulation for the sustained activation of ERK1/2, whereas EGF treatment of PC12 cells triggers cell proliferation and requires Ras stimulation for the transient activation of ERK1/2 (38,39). Similarly, GPCRs appear to mediate distinct cellular responses through the differential temporal activation of ERK1/2. For example, the angiotensin receptor mediates distinct cell responses via the transient and sustained activation of ERK1/2, which are mediated by the activation of $\mathrm{G}$ proteins and arrestin, respectively $(40,41)$. Interestingly, CXCR1 and CXCR2 trigger ERK1/2 activation, which is required for eliciting neutrophil responses, neuronal survival, and wound healing (24,43-46). To determine whether the $\mathrm{N}$-terminus-dependent receptor trafficking regulates the temporal activation of ERK1/2, we monitored the ERK1/2 activation triggered by the N2R1 and N1R2 chimeras. In agreement with previous studies, we found that CXCR1 and CXCR2 triggered a transient and sustained activation of ERK1/2, respectively (42). Most importantly, we observed that binding of IL-8 to N2R1 triggered a large and sustained activation of ERK1/2, similar to that with CXCR2, while binding of IL-8 to N1R2 and CXCR1 induced a small and transient activation of ERK1/2 (Figure 5). Interestingly, the R6A IL-8 mutant which triggered CXCR2 internalization like that with WT IL-8 also induced phosphorylation of ERK1/2, albeit with a lower efficiency, most likely due to the low binding affinity of the R6A IL-8 mutant (Figure $3 \mathrm{~S}$ of the Supporting Information). These observations strongly suggest that receptor internalization also regulates the signaling pathways leading to the differential temporal activation of ERK1/2, which is central for signal specificity and phenotypic cellular responses.

\section{SUPPORTING INFORMATION AVAILABLE}

Displacement of [ ${ }^{125}$ I]IL-8 bound to COS-7 cells (Figure 1S), IL-8-induced intracellular Ca ${ }^{2+}$ mobilization in HEK-293 cells (Figure 2S), and IL-8-and R6A mutant-triggered phosphorylatrion of ERK1/2 in COS-7 cells (Figure 3S). This material is available free of charge via the Internet at http://pubs.acs.org. 


\section{DISCUSSION}

This study shows that interactions between the N-loop of IL-8 and the receptor's N-termini play a major role in the rate of receptor internalization, which in turn regulates the temporal and spatial activation profile of ERK1/2, a major determinant of signal specificity and biological outcome. We initially showed that residues in the N-loop sequence of ELR chemokines is the major determinant for the internalization of CXCR2 and most likely underlies the distinct cellular responses mediated by these chemokines. Interestingly, the putative activation motif ELR of chemokines is not required for the chemokine-induced receptor internalization; i.e., the low-affinity "inactive" IL-8 mutant R6A triggered receptor internalization and activation of ERK1/2 just like WT IL-8. These findings suggest that the rate of receptor internalization is not coupled to neutrophil responses such as chemotaxis, degranulation, or superoxide production. On the basis of studies with receptor chimeras, we established that the N-termini of CXCR1 and CXCR2 contain the molecular information for setting the rate of receptor internalization, in contrast to the long-held view that the $\mathrm{C}$-terminal receptor domains are the major determinants for this process $(25,26)$. Here we argue that such disruptions of the receptor scaffold as $\mathrm{C}$-terminal truncation will preclude intramolecular signal transmission from the $\mathrm{N}$-terminus to the intracellular domains of the receptor, thus preventing stabilization of the conformational states of the receptor, leading to receptor internalization. In addition, our results with receptor chimeras support the view that the cores of CXCR1 and CXCR2, including the transmembrane domains and loops, operate as flexible scaffolds whose conformations are determined by the interactions of the chemokines with the receptor Nterminal domain. A recent report by Nasser et al. (49) has shown that the rates of internalization of the CXCR2 mutant (D199V) or the receptor chimera, in which the second extracellular loop of CXCR2 was replaced with the second extracellular loop of CXCR1, were similar or lower than that for CXCR1, respectively. In contrast, the CXCR1 mutant (V190D) and the reciprocal chimera, in which the second extracellular loop of CXCR1 was replaced with the second extracellular loop of CXCR2, were inactive. These results suggest that disruption of the receptor core precludes the signal transmission that leads to receptor internalization. Also, in contrast to our findings, the rates of internalization of the $\mathrm{N}$ chimeras, in which the extracellular $\mathrm{N}$-domains were swapped, were different from those we report here, although the chimera corresponding to N2R1 did not bind [ $\left.{ }^{125} \mathrm{I}\right] \mathrm{IL}-8$. These observations suggest that the receptor $\mathrm{N}$-terminus plays critical roles, including the internalization of the receptor and the phenotypic function of these receptors.

An important finding in this study is that the rate of receptor internalization regulates the temporal activation of ERK1/2, which is central for eliciting specific cellular responses such as neuronal survival and cell death $(37,45,46)$. Because the high-level and sustained activation of ERK1/2 is coupled to the fast rate of CXCR2 internalization, we suggest that the receptor regulates the CXCR2/ERK signaling pathway via a $G$ protein-independent mechanism from an intracellular compartment, similar to the ERK1/2 activation mediated by the angiotensin receptor and the nerve growth factor (38-41). A fundamental question is what receptormediated cellular functions are coupled to receptor trafficking and temporal activation of ERK1/2. We suggest that neuroprotection and wound healing are mediated by CXCR2, which triggers a sustained activation of ERK1/2 via a largely PTX-insensitive signaling pathway emanating from an intracellular compartment $(10,24,45)$. On the other hand, the receptor/ ERK1/2 signaling events mediated by $G$ proteins at the plasma membrane are important for neutrophil activation, which is enhanced when receptors are unable to undergo internalization $(26,29,44)$.

Previous studies have suggested that internalization of CXCR2 is required for chemotaxis on the basis of the fact that $\mathrm{C}$-terminal mutants of CXCR2, which were unable to undergo internalization, failed to mediate chemotaxis $(50,51)$. However, whereas chemotaxis is 
completely abolished in cells pretreated with pertussis toxin, receptor internalization is not affected (7), suggesting that CXCR2 mediated chemotaxis and internalization via distinct pathways. We showed that the IL-8 mutant R6A triggered internalization of CXCR2 as wildtype IL-8 (Figure 3), although this mutant failed to induce chemotaxis of neutrophils (20); further the chemokine GCP-2, which induced CXCR2 internalization at rates much lower than that of IL-8 (Figure 1), induced chemotaxis as effectively as IL-8 (52). These observations indicate that chemotaxis and CXCR2 internalization are not strictly coupled processes.

Our studies support the hypothesis that signal specificity is determined by the nature of the site 1 interaction (Figure 6), which leads to the stabilization of one or more conformational signaling states. On this basis, binding of IL-8 to CXCR1 would stabilize a receptor signaling state in the plasma membrane, whereas binding of IL-8 to CXCR2 would stabilize a signaling state in an intracellular compartment. This agrees with flow-cytometry analysis and immunoelectron microscopic localization of CXCR1 and CXCR2 in skin mast cells, which indicated that CXCR1 is on the cell surface whereas CXCR2 is localized in intracellular vesicles (47). On the other hand, the interactions of the ELR motif with the receptor (site 2, Figure 6) are involved in the activation mechanism, once the receptor is stabilized into specific conformational signaling states by the interaction of the $\mathrm{N}$-loop with the receptor's $\mathrm{N}$-terminal domain. Again, this view is supported by earlier observations where chemokine IP-10 mutants containing ELR failed to activate neutrophils, unless the N-loop sequence of IL-8 was also transplanted into these mutants (17).

In conclusion, the interaction of the receptors' N-terminal domains with the N-loop of ELR chemokines regulates the transport of the receptor from the plasma membrane into an intracytoplasmatic compartment, thus modulating the receptor signaling via $\mathrm{G}$ proteindependent and a $\mathrm{G}$ protein-independent mode. The combination between these two modes of signaling could determine the temporal activation of ERK1/2 to elicit signal specificity. Our data suggest the likely molecular basis for the shaping of the multiple cellular responses mediated by CXCR1 and CXCR2 by remodeling the interfacial surface at the $\mathrm{N}$-terminus of the receptor and the N-loop of chemokines.

\section{REFERENCES}

1. Baggiolini M. Chemokines and leukocyte traffic. Nature 1998;392:565-568. [PubMed: 9560152]

2. Onuffer JJ, Horuk R. Chemokines, chemokine receptors and small-molecule antagonists: Recent developments. Trends Pharmacol. Sci 2002;23:459-467. [PubMed: 12368070]

3. Thelen M. Dancing to the tune of chemokines. Nat. Immunol 2001;2:129-134. [PubMed: 11175805]

4. Ben-Baruch A, Bengali K, Tani K, Xu L, Oppenheim JJ, Wang JM. IL-8 and NAP-2 differ in their capacities to bind and chemoattract 293 cells transfected with either IL-8 receptor type A or type B. Cytokine 1997;9:37-45. [PubMed: 9067094]

5. Ben-Baruch A, Grimm M, Bengali K, Evans GA, Chertov O, Wang JM, Howard OM, Mukaida N, Matsushima K, Oppenheim JJ. The differential ability of IL-8 and neutrophil-activating peptide-2 to induce attenuation of chemotaxis is mediated by their divergent capabilities to phosphorylate CXCR2 (IL-8 receptor B). J. Immunol 1997;158:5927-5933. [PubMed: 9190946]

6. Damaj BB, McColl SR, Neote K, Hebert CA, Naccache PH. Diverging signal transduction pathways activated by interleukin 8 (IL-8) and related chemokines in human neutrophils. IL- 8 and Gro- $\alpha$ differentially stimulate calcium influx through IL-8 receptors A and B. J. Biol. Chem 1996;271:2054020544. [PubMed: 8702797]

7. Feniger-Barish R, Belkin D, Zaslaver A, Gal S, Dori M, Ran M, Ben-Baruch A. GCP-2-induced internalization of IL-8 receptors: Hierarchical relationships between GCP-2 and other ELR ${ }^{+}-\mathrm{CXC}$ chemokines and mechanisms regulating CXCR2 internalization and recycling. Blood 2000;95:15511559. [PubMed: 10688807] 
8. Katancik JA, Sharma A, de Nardin E. Interleukin 8, neutrophil-activating peptide-2 and GRO- $\alpha$ bind to and elicit cell activation via specific and different amino acid residues of CXCR2. Cytokine 2000;12:1480-1488. [PubMed: 11023662]

9. Katancik JA, Sharma A, Radel SJ, De Nardin E. Mapping of the extracellular binding regions of the human interleukin-8 type B receptor 1997;232:663-668.

10. Devalaraja RM, Nanney LB, Du J, Qian Q, Yu Y, Devalaraja MN, Richmond A. Delayed wound healing in CXCR2 knockout mice. J. Invest. Dermatol 2000;115:234-244. [PubMed: 10951241]

11. Rosenkilde MM, Schwartz TW. The chemokine system: A major regulator of angiogenesis in health and disease. APMIS 2004;112:481-495. [PubMed: 15563311]

12. Tran PB, Miller RJ. Chemokine receptors: Signposts to brain development and disease. Nat. Rev. Neurosci 2003;4:444-455. [PubMed: 12778117]

13. Ahuja SK, Murphy PM. The CXC chemokines growth-regulated oncogene (GRO) $\alpha$, GRO $\beta$, GRO $\gamma$, neutrophil-activating peptide-2, and epithelial cell-derived neutrophil-activating peptide-78 are potent agonists for the type B, but not the type A, human interleukin- 8 receptor. J. Biol. Chem 1996;271:20545-20550. [PubMed: 8702798]

14. LaRosa GJ, Thomas KM, Kaufmann ME, Mark R, White M, Taylor L, Gray G, Witt D, Navarro J. Amino terminus of the interleukin-8 receptor is a major determinant of receptor subtype specificity. J. Biol. Chem 1992;267:25402-25406. [PubMed: 1281158]

15. Rajagopalan L, Rajarathnam K. Structural basis of chemokine receptor function: A model for binding affinity and ligand selectivity. Biosci. Rep 2006;26:325-339. [PubMed: 17024562]

16. Clark-Lewis I, Dewald B, Geiser T, Moser B, Baggiolini M. Platelet factor 4 binds to interleukin 8 receptors and activates neutrophils when its $\mathrm{N}$ terminus is modified with Glu-Leu-Arg. Proc. Natl. Acad. Sci. U.S.A 1993;90:3574-3577. [PubMed: 8475106]

17. Clark-Lewis I, Dewald B, Loetscher M, Moser B, Baggiolini M. Structural requirements for interleukin- 8 function identified by design of analogs and CXC chemokine hybrids. J. Biol. Chem 1994;269:16075-16081. [PubMed: 8206907]

18. Leong SR, Kabakoff RC, Hebert CA. Complete mutagenesis of the extracellular domain of interleukin-8 (IL-8) type A receptor identifies charged residues mediating IL-8 binding and signal transduction. J. Biol. Chem 1994;269:19343-19348. [PubMed: 8034699]

19. Lowman HB, Slagle PH, DeForge LE, Wirth CM, Gillece-Castro BL, Bourell JH, Fairbrother WJ. Exchanging interleukin- 8 and melanoma growth-stimulating activity receptor binding specificities. J. Biol. Chem 1996;271:14344-14352. [PubMed: 8662882]

20. Moser B, Dewald B, Barella L, Schumacher C, Baggiolini M, Clark-Lewis I. Interleukin-8 antagonists generated by N-terminal modification. J. Biol. Chem 1993;268:7125-7128. [PubMed: 8463247]

21. Skelton NJ, Quan C, Reilly D, Lowman H. Structure of a CXC chemokine-receptor fragment in complex with interleukin-8. Structure 1999;7:157-168. [PubMed: 10368283]

22. Jones SA, Wolf M, Qin S, Mackay CR, Baggiolini M. Different functions for the interleukin 8 receptors (IL-8R) of human neutrophil leukocytes: NADPH oxidase and phospholipase D are activated through IL-8R1 but not IL-8R2. Proc. Natl. Acad. Sci. U.S.A 1996;93:6682-6686. [PubMed: 8692878]

23. Chakrabarti S, Patel KD. Regulation of matrix metalloproteinase-9 release from IL-8-stimulated human neutrophils. J. Leukocyte Biol 2005;78:279-288. [PubMed: 15831558]

24. Watson K, Fan GH. Macrophage inflammatory protein 2 inhibits $\beta$-amyloid peptide (1-42)-mediated hippocampal neuronal apoptosis through activation of mitogen-activated protein kinase and phosphatidylinositol 3-kinase signaling pathways. Mol. Pharmacol 2005;67:757-765. [PubMed: 15608143]

25. Prado GN, Suzuki H, Wilkinson N, Cousins B, Navarro J. Role of the C terminus of the interleukin 8 receptor in signal transduction and internalization. J. Biol. Chem 1996;271:19186-19190. [PubMed: 8702597]

26. Richardson RM, Marjoram RJ, Barak LS, Snyderman R. Role of the cytoplasmic tails of CXCR1 and CXCR2 in mediating leukocyte migration, activation, and regulation. J. Immunol 2003;70:29042911. [PubMed: 12626541]

27. Reiter E, Lefkowitz RJ. GRKs and $\beta$-arrestins: Roles in receptor silencing, trafficking and signaling. Trends Endocrinol. Metab 2006;17:159-165. [PubMed: 16595179] 
28. Rajarathnam K, Prado GN, Fernando H, Clark-Lewis I, Navarro J. Probing receptor binding activity of interleukin-8 dimer using a disulfide trap. Biochemistry 2006;45:7882-7888. [PubMed: 16784240]

29. Suetomi K, Lu Z, Heck T, Wood TG, Prusak DJ, Dunn KJ, Navarro J. Differential mechanisms of recognition and activation of interleukin-8 receptor subtypes. J. Biol. Chem 1999;274:11768-11772. [PubMed: 10206993]

30. Thomas KM, Taylor L, Navarro J. The interleukin-8 receptor is encoded by a neutrophil-specific cDNA clone, F3R. J. Biol. Chem 1991;266:14839-14841. [PubMed: 1714446]

31. Lu Z, Murray KS, Van Cleave V, LaVallie ER, Stahl ML, McCoy JM. Expression of thioredoxin random peptide libraries on the Escherichia coli cell surface as functional fusions to flagellin: A system designed for exploring protein-protein interactions. Bio/Technology 1995;13:366-372. [PubMed: 9634778]

32. Williams G, Borkakoti N, Bottomley GA, Cowan I, Fallowfield AG, Jones PS, Kirtland SJ, Price GJ, Price L. Mutagenesis studies of interleukin-8. Identification of a second epitope involved in receptor binding. J. Biol. Chem 1996;271:9579-9586. [PubMed: 8621632]

33. Hebert CA, Vitangcol RV, Baker JB. Scanning mutagenesis of interleukin-8 identifies a cluster of residues required for receptor binding. J. Biol. Chem 1991;266:18989-18994. [PubMed: 1918013]

34. Rose JJ, Foley JF, Murphy PM, Venkatesan S. On the mechanism and significance of ligand-induced internalization of human neutrophil chemokine receptors CXCR1 and CXCR2. J. Biol. Chem 2004;279:24372-24386. [PubMed: 15028716]

35. Hoeller D, Volarevic S, Dikic I. Compartmentalization of growth factor receptor signalling. Curr. Opin. Cell Biol 2005;17:107-111. [PubMed: 15780584]

36. Stork PJ. Directing NGF's actions: It's a Rap. Nat. Cell Biol 2005;7:338-339. [PubMed: 15803132]

37. Friedman A, Perrimon N. A functional RNAi screen for regulators of receptor tyrosine kinase and ERK signalling. Nature 2006;444:230-234. [PubMed: 17086199]

38. Kao S, Jaiswal RK, Kolch W, Landreth GE. Identification of the mechanisms regulating the differential activation of the mapk cascade by epidermal growth factor and nerve growth factor in PC12 cells. J. Biol. Chem 2001;276:18169-18177. [PubMed: 11278445]

39. York RD, Molliver DC, Grewal SS, Stenberg PE, McCleskey EW, Stork PJ. Role of phosphoinositide 3-kinase and endocytosis in nerve growth factor-induced extracellular signal-regulated kinase activation via Ras and Rap1. Mol. Cell. Biol 2000;20:8069-8083. [PubMed: 11027277]

40. Ahn S, Shenoy SK, Wei H, Lefkowitz RJ. Differential kinetic and spatial patterns of $\beta$-arrestin and G protein-mediated ERK activation by the angiotensin II receptor. J. Biol. Chem 2004;279:3551835525. [PubMed: 15205453]

41. Daniels D, Yee DK, Faulconbridge LF, Fluharty SJ. Divergent behavioral roles of angiotensin receptor intracellular signaling cascades. Endocrinology 2005;146:5552-5560. [PubMed: 16123155]

42. Shyamala V, Khoja H. Interleukin-8 receptors R1 and R2 activate mitogen-activated protein kinases and induce c-fos, independent of Ras and Raf-1 in Chinese hamster ovary cells. Biochemistry 1998;37:15918-15924. [PubMed: 9843397]

43. Fuhler GM, Knol GJ, Drayer AL, Vellenga E. Impaired interleukin-8- and GRO $\alpha$-induced phosphorylation of extracellular signal-regulated kinase result in decreased migration of neutrophils from patients with myelodysplasia. J. Leukocyte Biol 2005;77:257-266. [PubMed: 15561756]

44. Knall C, Young S, Nick JA, Buhl AM, Worthen GS, Johnson GL. Interleukin-8 regulation of the Ras/ Raf/mitogen-activated protein kinase pathway in human neutrophils. J. Biol. Chem 1996;271:28322838. [PubMed: 8576262]

45. Xia M, Hyman BT. GRO $\alpha / \mathrm{KC}$, a chemokine receptor CXCR2 ligand, can be a potent trigger for neuronal ERK1/2 and PI-3 kinase pathways and for tau hyperphosphorylation-a role in Alzheimer's disease? J. Neuroimmunol 2002;122:55-64. [PubMed: 11777543]

46. Zhao M, Wimmer A, Trieu K, Discipio RG, Schrauf-statter IU. Arrestin regulates MAPK activation and prevents NADPH oxidase-dependent death of cells expressing CXCR2. J. Biol. Chem 2004;279:49259-49267. [PubMed: 15364949]

47. Lippert U, Artuc M, Grutzkau A, Moller A, Kenderessy-Szabo A, Schadendorf D, Norgauer J, Hartmann K, Schweitzer-Stenner R, Zuberbier T, Henz BM, Kruger-Krasagakes S. Expression and 
functional activity of the IL-8 receptor type CXCR1 and CXCR2 on human mast cells. J. Immunol 1998;161:2600-2608. [PubMed: 9725262]

48. Gayle RB III, Sleath PR, Srinivason S, Birks CW, Weerawarna KS, Cerretti DP, Kozlosky CJ, Nelson $\mathrm{N}$, Vanden Bos T, Beckmann MP. Importance of the amino terminus of the interleukin- 8 receptor in ligand interactions. J. Biol. Chem 1993;268:7283-7289. [PubMed: 8463264]

49. Nasser MW, Raghuwanshi SK, Malloy KM, Gangavarapu P, Shim JY, Rajarathnam K, Richardson RM. CXCR1 and CXCR2 activation and regulation. Role of aspartate 199 of the second extracellular loop of CXCR2 in CXCL8-mediated rapid receptor internalization. J. Biol. Chem 2007;282:69066915. [PubMed: 17204468]

50. Fan G-H, Yang W, Wang X-J, Qian Q, Richmond A. Identification of a motif in the carboxyl terminus of CXCR2 that is involved in adaptin 2 binding and receptor internalization. Biochemistry 2001;40:791-800. [PubMed: 11170396]

51. Sai J, Walker G, Wikswo J, Richmond A. The IL sequence in the LLLKIL motif in CXCR2 is required for full ligand-induced activation of Erk, Akt, and chemotaxis in HL-60 cells. J. Biol. Chem 2006;281:35931-35941. [PubMed: 16990258]

52. Wolf M, Delgado MB, Jones SA, DeWald B, Clark-Lewis I, Baggiolini M. Granulocyte chemotactic protein 2 acts via both IL-8 receptors, CXCR1 and CXCR2. Eur. J. Immunol 1998;28:164-170. [PubMed: 9485196] 


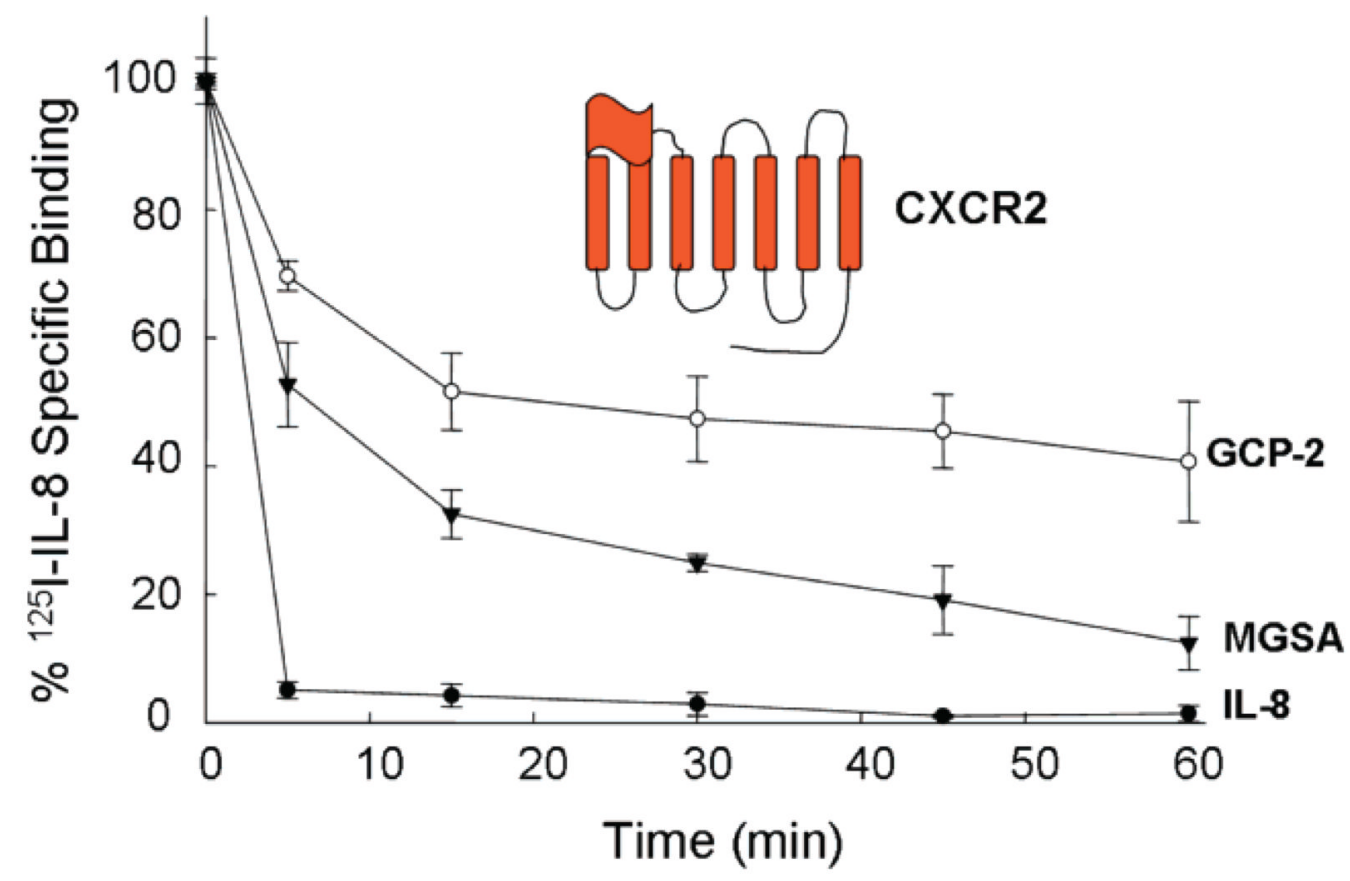

IL-8 SAKELRCQCI KTYSKPFHPK EIKELRVIES GPHCANTEII VKLSDGRELC LDPKENWVQR VVEKFLKRAE NS MGSA ASVATELRCQCI QTLQ-GIHPKNIQSVNVKSP- GPHCAQTEVI ATLKNGRKAC LNPASPIVKK IIEKMLNSDK SN GCP-2 SAVLTELRCTCL RVTLR-VNPKFIGKLQVFPA- GPQCSKVEVV ASLKNGKQVC LDPEAPFLKK VIQKILDSGNK

FIGURE 1.

ELR chemokines induce internalization of CXCR2. COS-7 cells expressing CXCR2 were treated with saturating concentrations $(100 \mathrm{nM})$ of IL-8 $(\bullet)$, MGSA $(\boldsymbol{\nabla})$, or GCP-2 (O) at 37 ${ }^{\circ} \mathrm{C}$ for various amounts of time. After an acid wash, the surface receptors were assessed by $\left[{ }^{125} \mathrm{I}\right] \mathrm{IL}-8$ binding at $4{ }^{\circ} \mathrm{C}(25)$. Sequence alignments of IL-8, MGSA, and GCP-2 are shown with their corresponding secondary structure domains; the thick red line identifies the conserved ELR triad, and the thick blue line identifies the divergent N-loop sequences. 


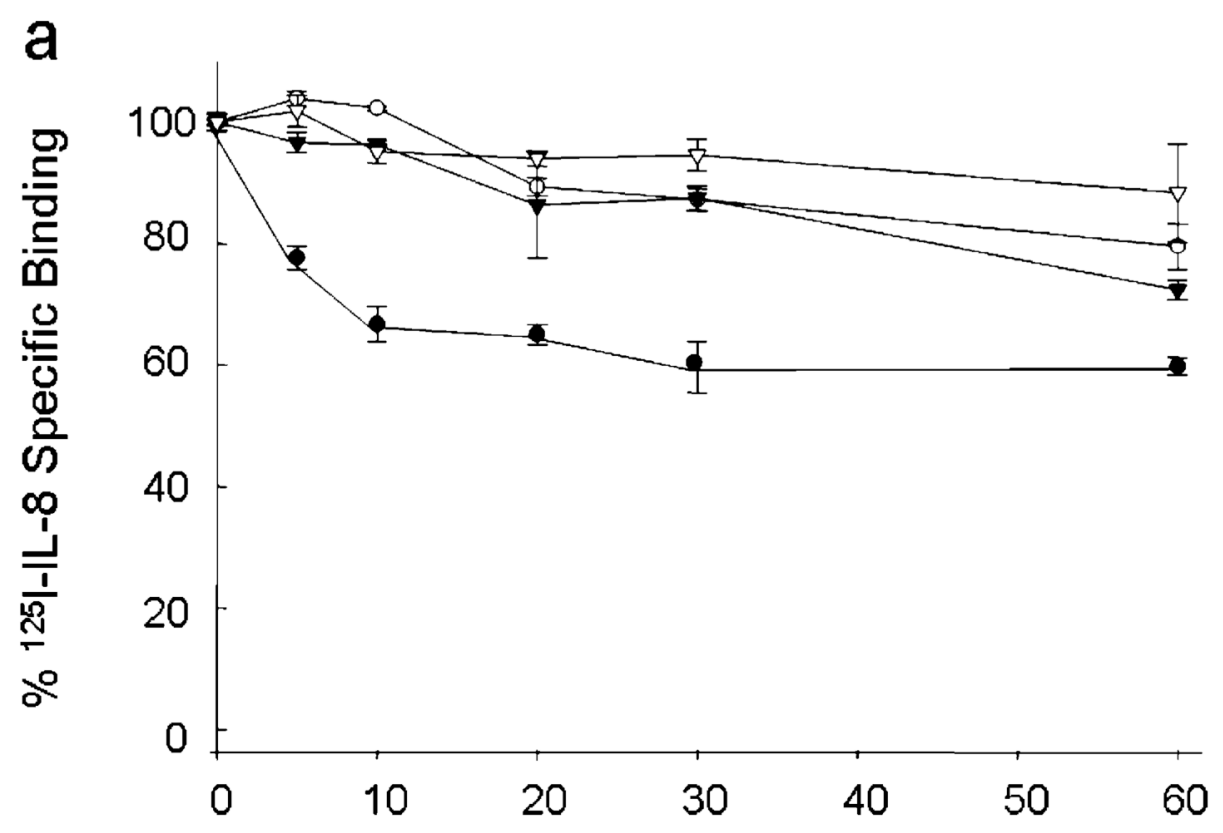

b

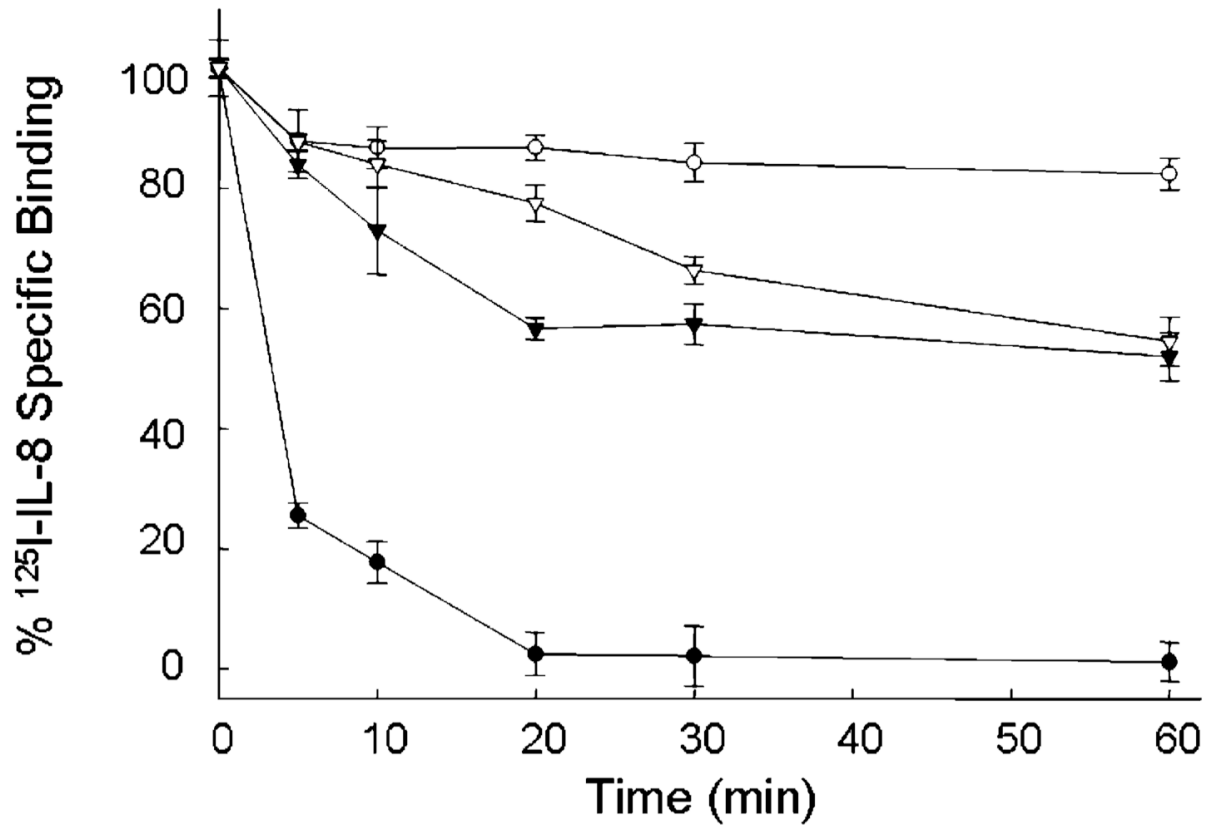

FIGURE 2.

N-Loop IL-8 mutants fail to trigger internalization of CXCR1 and CXCR2. COS-7 cells expressing CXCR1 (a) or CXCR2 (b) were treated with saturating concentrations (100 nM) of $\mathrm{IL}-8(\bullet), \mathrm{H} 18 \mathrm{~A}(\circ), \mathrm{F} 21 \mathrm{~A}(\boldsymbol{\nabla})$, or H18A/F21A $(\nabla)$ at $37{ }^{\circ} \mathrm{C}$ for different amounts of time. After an acid wash, the surface IL-8 receptors were assessed by [ $\left.{ }^{125} \mathrm{I}\right] \mathrm{IL}-8$ binding (25). 


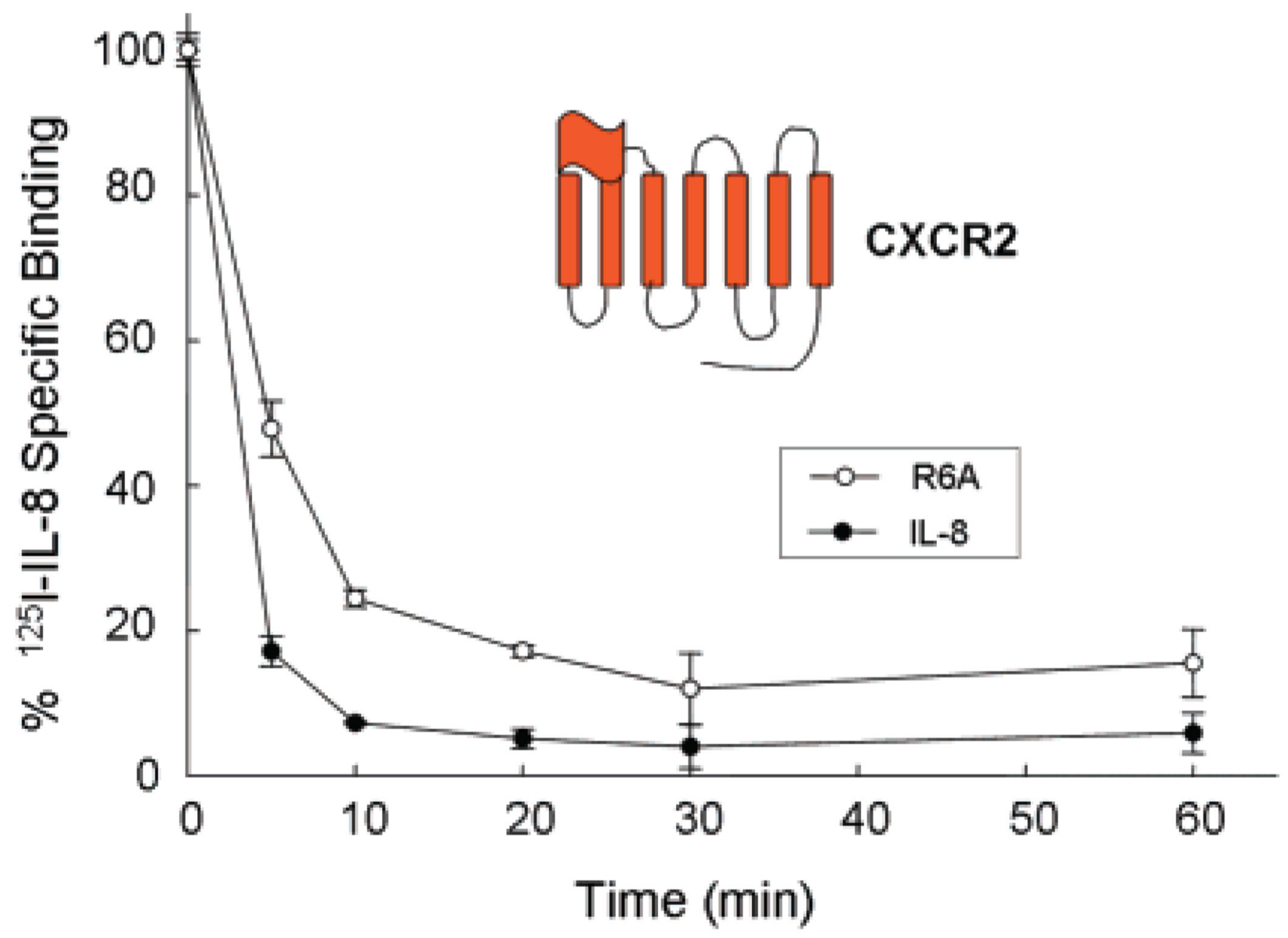

FIGURE 3.

IL-8 and the ELR mutant (R6A) induce internalization of CXCR2. COS-7 cells expressing CXCR2 were treated with $100 \mathrm{nM}$ IL-8 or $1 \mu \mathrm{M}$ R6A for different amounts of time. After an acid wash, the cell surface receptors were assessed by [ $\left.{ }^{125} \mathrm{I}\right] \mathrm{IL}-8$ binding (25). 


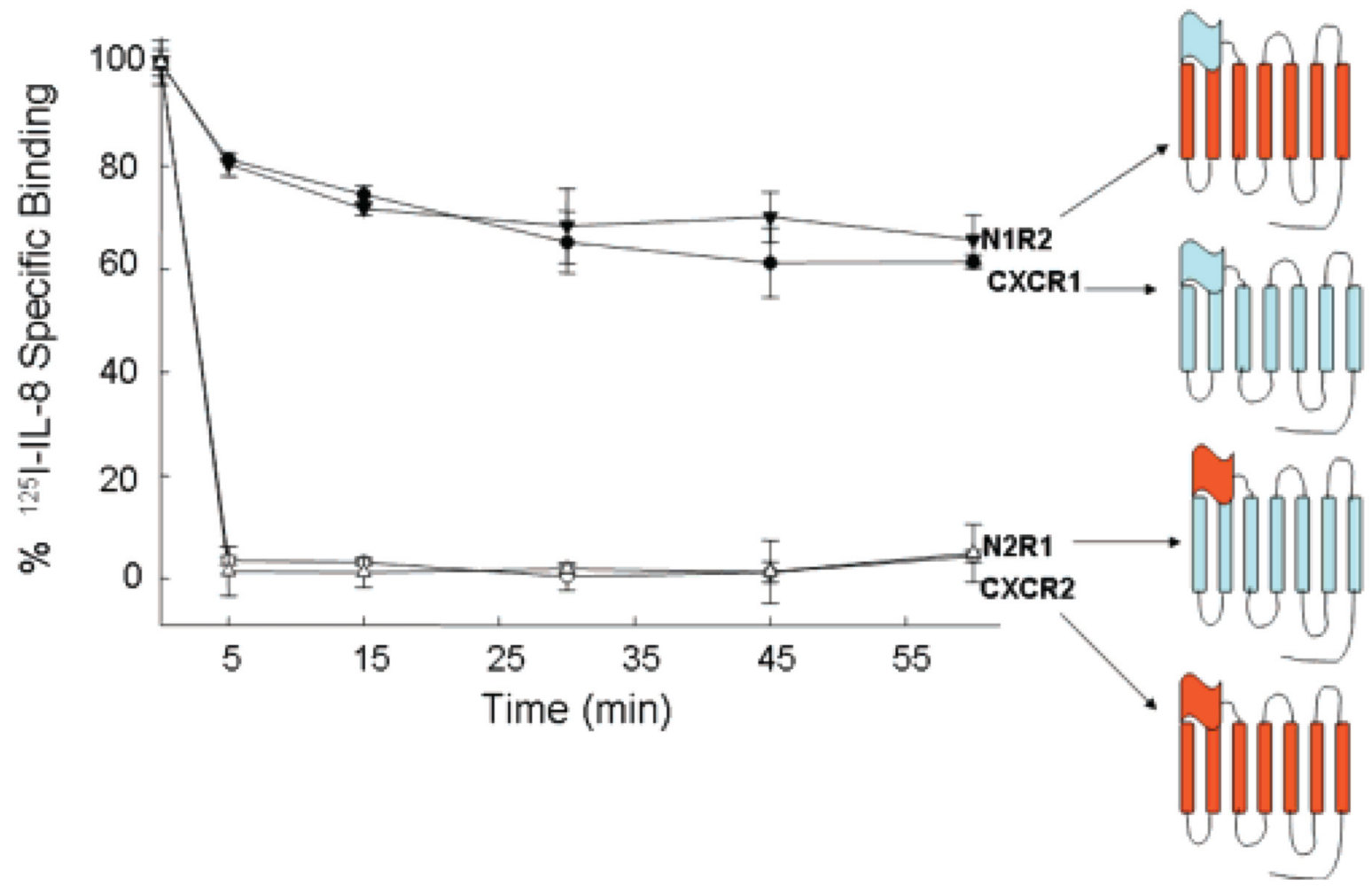

FIGURE 4.

Receptor N-termini determine the rate of receptor internalization. COS-7 cells expressing CXCR1 $(\bullet), \operatorname{CXCR} 2(\circ), \mathrm{N} 1 \mathrm{R} 2(\boldsymbol{\nabla})$, and N2R1 $(\Delta)$ were treated with $100 \mathrm{nM} \mathrm{IL-8} \mathrm{for} \mathrm{various}$ amounts of time. After an acid wash, the cell surface receptors were assessed by $\left[{ }^{125} \mathrm{I}\right] \mathrm{IL}-8$ binding (25). 
a

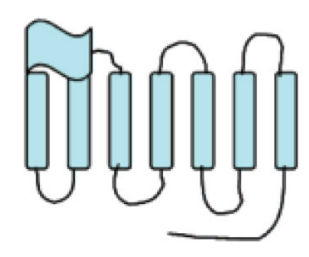

ERK1
CXCR1

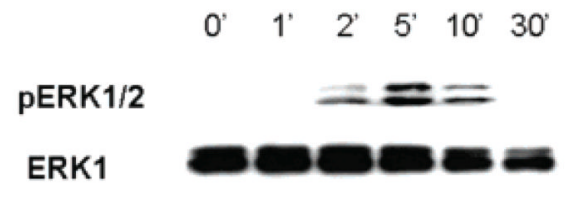

N1R2
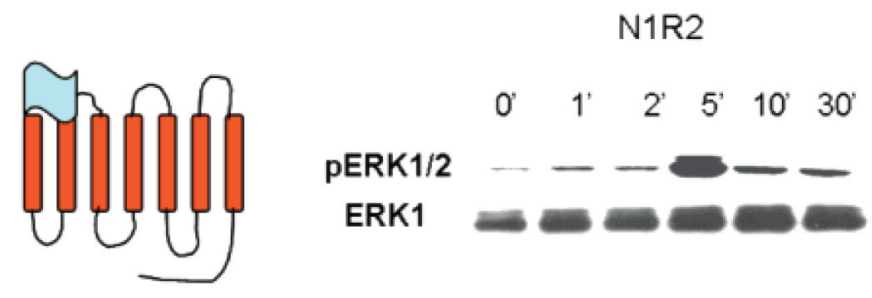

b

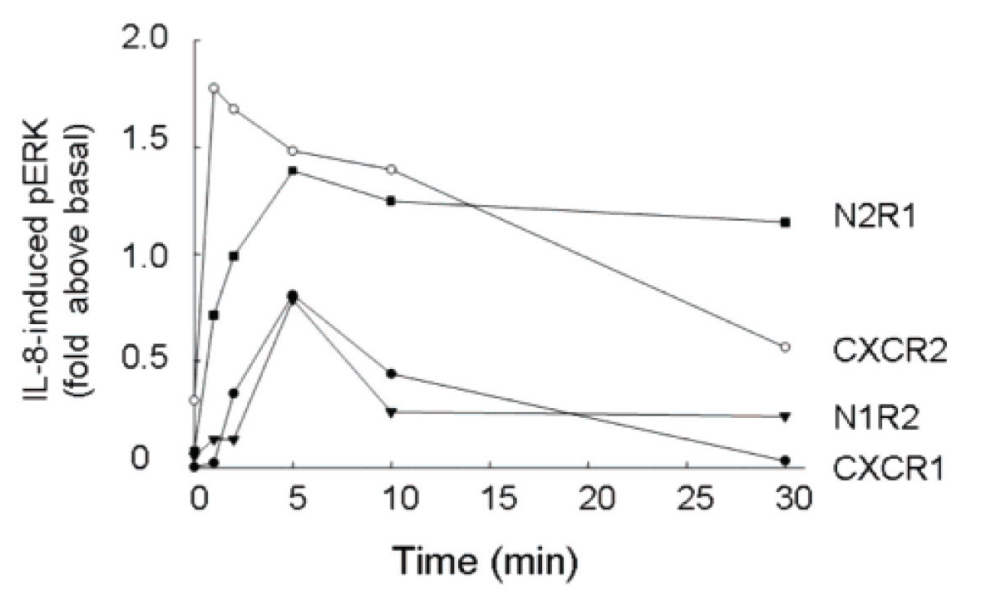

FIGURE 5.

Receptor N-termini determine the activation profile of ERK1/2. COS-7 cells transfected with CXCR1, CXCR2, N1R2, or N2R1 were treated with $100 \mathrm{nM} \mathrm{IL-8} \mathrm{for} \mathrm{different} \mathrm{amounts} \mathrm{of}$ time. The phosphorylated ERK1/2 was analyzed by Western blot analysis (a). The levels of phospho-ERK1/2 relative to the total ERK were plotted (b). Data are representative of three independent experiments. 


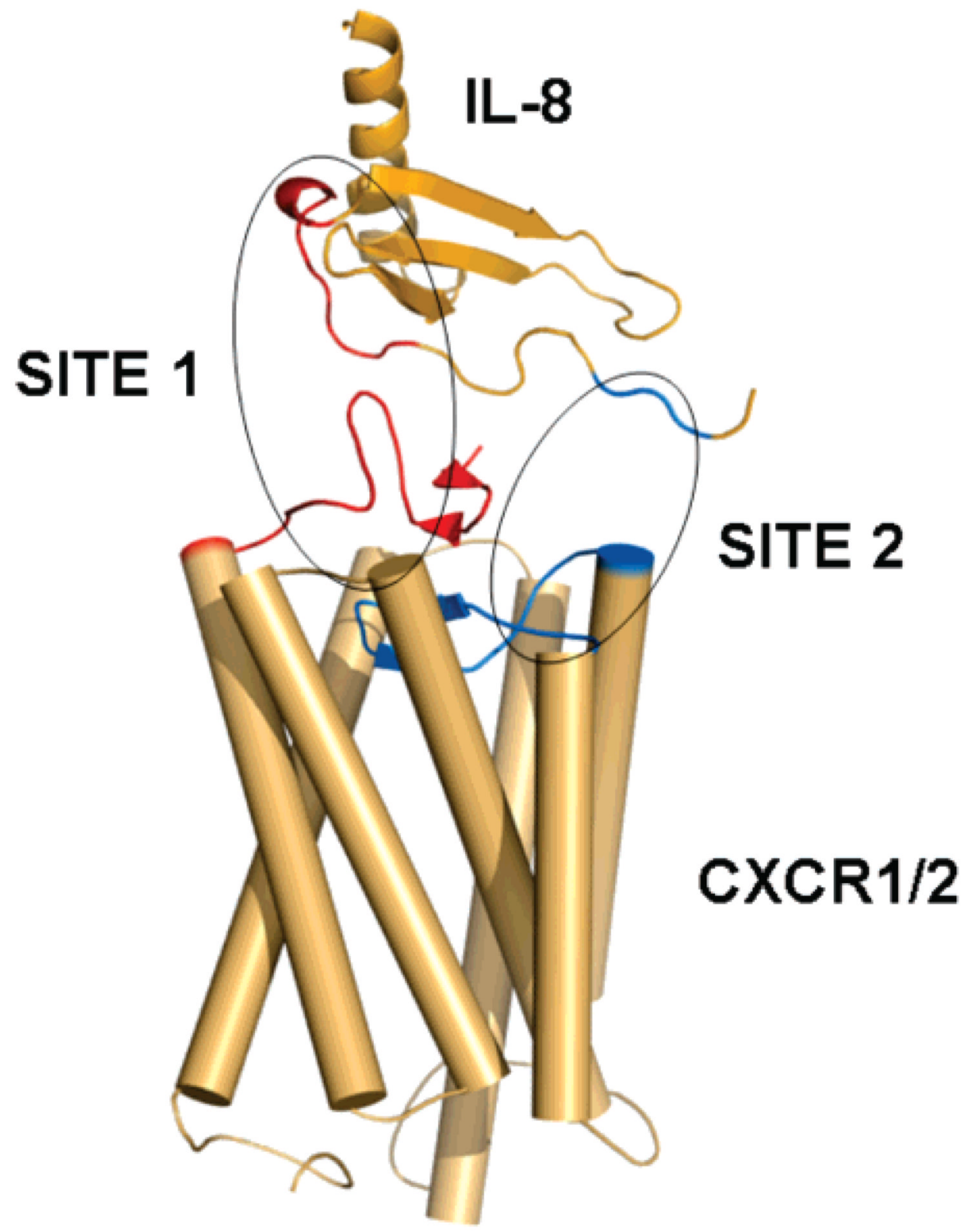

FIGURE 6.

Hypothetical model of binding of IL-8 to its cognate receptor. The putative interacting surfaces of the receptor and IL-8 (sites 1 and 2) are encircled. Site 1 represents the interaction of the Nterminus of the receptor with the N-loop of IL-8, whereas site 2 represents the interaction of the extracellular loops of the receptor with the ELR triad of IL-8. 